\title{
Penguatan Peran Takmir Masjid dalam Tanggap Bencana Gempa Bumi di Desa Bangunharjo
}

\author{
Muthmainnah $^{1}$, Toto Hermawan ${ }^{2 *}$, Suryanto ${ }^{3}$, Indra Suharyanto ${ }^{4}$, Abdul Mughits ${ }^{5}$, \\ Akhmad Muhaini ${ }^{6}$, Ali Imron ${ }^{7}$ \\ ${ }^{1234}$ Universitas Cokroaminoto Yogyakarta, ${ }^{5}$ UIN Sunan Kalijaga, \\ ${ }^{6}$ STAI An-Nawawi Purworejo, ${ }^{7}$ KUA Kecamatan Sewon Kabupaten Bantul \\ *Penulis Koresponden, email: toto.hermawan@mail.ugm.ac.id
}

\begin{abstract}
Abstrak
Tujuan pelaksanaan pengabdian masyarakat adalah mendorong partisipasi aktif dari para takmir masjid di Desa Bangunharjo Kecamatan Sewon Kabupaten Bantul dalam mitigasi bencana gempa bumi tektonik, khususnya. kegiatan diarahkan pada pengayaan pengetahuan dan teknologi tentang pengurangan dampak gempa bumi kepada masyarakat secara berkelanjutan oleh pemimpin dan pengurus masjid agar perannya bisa efektif dalam kegiatan mitigasi. Pendekatan partisipatif sesuai menjadi pilihan dalam pelaksanan pembekalan untuk memotivasi pengurus masjid terlibat penuh kegiatan mitigasi maupun kesiapan bertindak dan berkordinasi saat kenyataan gempa bumi terjadi. Catatan penting dari masyarakat dapat ditindaklanjuti antara lain, kebutuhan pendampingan ternyata sangat nyata terutama dari informasi dan teknologi dalam penanganan permasalahan gempa bumi dan pemantapan sosialisasi dalam bentuk kurikulum yang lebih permanen dan mudah dilaksanakan di masjid, terutama bagi anak-anak yang belajar di TPA maupun jama'ah pengajian. Segmentasi tersebut diharapkan menjadi keberhasilan program mitigasi bencana terutama yang berkenaan dengan persoalan mitigasi gempa bumi yang berkaitan dengan bidang keagamaan.
\end{abstract}

Kata Kunci: masjid, takmir, mitigasi, gempa bumi

\begin{abstract}
The purpose of implementing community service is to encourage active participation of mosque takmirs in Bangunharjo Village, Sewon District, Bantul Regency to strengthen their role in handling tectonic earthquakes, especially mitigation. For this reason, activities are directed at enriching knowledge and technology about reducing the impact of earthquakes on the community in a sustainable manner by mosque leaders and administrators so that their role can be effective in mitigation activities. The appropriate participatory approach is an option in carrying out debriefing to motivate mosque administrators to be fully involved in mitigation activities as well as readiness to act and coordinate when an earthquake occurs. Important notes from the community that can be followed up are, among others, the need for assistance is very real, especially from information and technology in handling earthquake problems and strengthening socialization in the form of a curriculum that is more permanent and easy to implement in mosques, especially for children studying in TPA and congregation recitation. This segmentation is expected to be the success of disaster mitigation programs,
\end{abstract}

This is an open access article under the (C-BY-SA license @) (1) () 
Muthmainnah, Toto Hermawan, Suryanto, Indra Suharyanto,

Abdul Mughits, Akhmad Muhaini, Ali Imron

especially those relating to earthquake mitigation issues related to the religious sector.

Keywords: mitigation, mosques, takmir, earthquakes

\section{Pendahuluan}

Tinjauan geologi telah menegaskan bahwa Indonesia sering terjadi bencana gempa bumi karena mempunyai banyak gunung berapi dan pergerakan lempeng yang masih aktif (Aditya 2010). Jenis gempa yang sering terjadi di Indonesia lainnya berupa gempa bumi tektonik karenapergeseran lempeng-lempeng tektonik yang ada pada kerak bumi (lithosphere) secara mendadak yang mempunyai kekuatan dari yang sangat kecil hingga yang sangat besar.

Di antara sekian banyak gempa tersebut, sekitar 100 gempa pertahun menimbulkan bencana kematian dan kerusakan yang parah. Peraturan Pemerintah RI Nomor 21 Tahun 2008 (PP 21 2008) Tentang Penyelenggaraan Penanggulangan Bencana telah dijelaskan pengertian bencana.

Peristiwa atau rangkaian peristiwa yang mengancam dan mengganggu kehidupan dan penghidupan masyarakat yang disebabkan, baik oleh faktor alam dan/atau faktor non-alam maupun faktor manusia sehingga mengakibatkan timbulnya korban jiwa manusia, kerusakan lingkungan, kerugian harta benda, dan dampak psikologis (RI 2008).

Propinsi Daerah Istimewa Yogyakarta (DIY) berdekatan dengan zona subduksi lempeng Indo-Australia terhadap lempeng Eurasia menjadi daerah rawan gempa bumi (Dwisiwi R.S. et al. 2012; Rakhman dan Kuswardani 2012). Selain rawan gempa bumi akibat aktivitas tumbukan lempeng, kerawanannya juga diakibatkan aktivitas beberapa sesar lokal di daratan. Struktur sesar terbentuk sebagai dampak desakan lempeng Indo-Australia pada bagian daratan Pulau Jawa (Setyawan dan Khakim 2012; Zaeniah 2013). Beberapa sistem sesar yang diduga masih aktif adalah Sesar Opak, Sesar Oya, Sesar Dengkeng, Sesar Progo, serta sesar mikro lainnya. Aktifnya dinamika penyusupan lempeng yang didukung oleh 
aktivitas sesar di daratan menyebabkan daerah Yogyakarta menjadi salah satu daerah dengan tingkat aktivitas kegempaan yang tinggi di Indonesia (Zaeniah 2013).

Pengalaman gempa bumi Yogyakarta tahun 2006 telah mensuratkan peran besar institusi agama dalam mengurangi dampak dan pemulihan pasca bencana gempa bumi. Sorotan terbesar adalah keberadaan masjid sebagai tempat penampungan sementara dan pusat logistik bagi pengungsi gempa bumi, tentu saja peran takmir sangat penting sebagai aktor yang memainkan peran ini (Dahalan et al. 2015; Mohit et al. 2014; Saputra et al. 2010). Belajar darinya, peran masjid bisa diperluas dengan menindaklajutinya sebagai bagian dalam kegiatan mitigasi bencana gempa bumi yang berdampak langsung kepada masyarakat dan jama'ahnya. Dengan demikian harapan untuk perwujudan masjid yang tangguh menghadapi segala bencana alam bisa terwujud.

Peran Takmir Masjid dalam pengurangan dampak bencana gempa bumi terutama sebagai pusat informasi dan pengetahuan bencana gempa bumi kemudian menjadi terasa besar apabila ditelaah lebih lanjut. Aspek peribadatan Islam juga terpengaruh karena gempa bumi. Pasca gempa bumi bisa menimbulkan kekurangan air yang berdampak pada pemanfaatan tayammum sebagai pengganti wudu sebelum melakukan salat.

Bencana Gempa bumi juga menjadi perhatian dalam kajian ilmu falak yang tidak sebatas penentuan kalender (Mughits 2016; Muthmainnah 2016).juga berpotensi pergeseran letak masjid, musalla, pekuburan dan tempat solat di rumah terhadap arah kiblat sebagai bagian unsur penting dalam salat wajib (Nuroini 2010). Akurasi arah Kiblat di Indonesia dihitung secara bersungguh-sungguh berdasarkan tata letak masjid ke arah kakbah di Mekkah (Arifin 2018; Mutmainnah 2017). Salah satu aplikasi penting adalah Google Earth (Arifin 2017)

Masjid telah menjadi lembaga social islam terdepan yang eksis dalam tanggap bencana gempa bumi karena fungsinya yang berdimensi kompleks dan diakui nyata bagi kesejahteraan jasmani dan rohani masyarakat sekitarnya (Mohit et al. 2014; Saputra et al. 2010). Semua kenyataan 
Muthmainnah, Toto Hermawan, Suryanto, Indra Suharyanto,

Abdul Mughits, Akhmad Muhaini, Ali Imron

memberikan peluang dan relevansi masjid sebagai pusat informasi dan pengetahuan pengurangan resiko gempa bumi. Peran pemerintah masih terbatas pada sebatas pemberian bantuan fisik. dan dilakukan hanya pada fase kedaruratan (Maarif 2012).

Masjid bisa berperan lebih jauh dalam mitigasi bencana alam di lingkungannya. Dalam PP 21 2008, Mitigasi ditegaskan sebagai, "Serangkaian upaya untuk mengurangi risiko bencana, baik melalui pembangunan fisik maupun penyadaran dan peningkatan kemampuan menghadapi ancaman bencana" (RI 2008). Tindakan-tindakan di dalamnya bertujuan untuk mengurangi kerusakan akibat dalam area domestik maupun publik terutama jiwa, harta benda, termasuk potensi dan akibat kerusakan infrastruktur fisik dan social.

Masjid sebagai wahana sosialisasi lingkungan hidup yang bersih telah diakui (Imroatun 2015). Bencana yang berdampak juga pada lingkungan telah membutuhkan peran takmir masjid lebih besar dalam mitigasi terutama sebagai pusat informasi dan pengetahuan bencana gempa bumi. Apabila ditelaah lebih lanjut bahwa aspek peribadatan Islam juga terpengaruh karena gempa bumi. Pasca gempa bumi bisa menimbulkan kekurangan air yang berdampak pada tayammum sebagai pengganti wudu sebelum melakukan salat. Gempa bumi juga berpotensi pergeseran letak masjid, musalla, pekuburan dan tempat solat di rumah terhadap arah kiblat sebagai bagian unsur penting dalam salat wajib (Saputra dkk., 2010).

Semua kenyataan memberikan peluang dan relevansi masjid sebagai pusat informasi dan pengetahuan pengurangan resiko gempa bumi. Untuk itu, pimpinan dan pengurus masjid yang berpengetahuan dan kemampuan serta proaktive dalam tanggap bencana menjadi tuntutan yang tak terelakkan. Perguruan Tinggi Keagamaan Islam (PTKI) pun tak bisa melepaskan diri dari tanggung jawab kemasyarakatan demikian. Keahlian yang dimiliki relevan bagi pendampingan takmir masjid. Pengalaman PTKI dalam pendampingan lingkungan hidup bagi majelis taklim dan takmir masjid (Nadjih dan Santoso 2015; Santoso, Nadjih, dan Samroni 2015), maupun pengembangan enterpreunership (Fauroni, Ahmad, dan Kostradiharto 2016; Musaropah et al. 
2019), bisa menjadi batu loncatan demikian untuk membekali pengetahuan tentang mitigasi bencana gempa bumi bidang keagamaan di wilayah pedesaan rawan gempa bumi.

\section{Metode}

Pengabdian kepada masyarakat dilaksanakan di desa Desa Bangunharjo Kecamatan Sewon Kabupaten Bantul dengan pendekatan kajian tindakan partisipatif, yang juga dikenal dengan penelitian tindakan kelas dalam pendidikan (Prihantoro dan Hidayat 2019), dengan peserta terdiri dari para takmir masjid di desa tersebut. Pengabdian diarahkan kepada materi mitigasi bencana gempa bumi sebagai bagian dari manajemen bencana di tahapan pra bencana. Pada tahapan ini kesiapan dan kewaspadaan terhadap gempa bumi, resiko beserta antisipasinya menjadi muatan penting untuk disebarluaskan kepada masyarakat dan pelaksana mitigasi.

Pengayaan pengetahuan dan teknologi masyarakat tentang pengurangan dampak gempa bumi kepada masyarakat harus dilaksanakan secara berkelanjutan oleh pemimpin dan pengurus masjid agar perannya bisa efektif dalam kegiatan mitigasi. Maka pembekalan terhadap para takmir masjid tentang mitigasi bencana gempa bumi diprioritaskan. Fokusnya kepada dampak gempa bumi dalam peribadatan terutama penentuan arah kiblat baik secara tradisional maupun modern hingga merata agar tidak menjadi sebab kekeliruan terhadap kenyataan arah kiblat yang ada di masyarakat desa Bangunharjo pasca gempa bumi.

Kegiatan pengabdian kemasyarakatan ini berupa; a) Pendampingan Fokus Group Discussion serial mitigasi bencana gempa bumi bagi pengurus masjid bagi pengembangan materi mitigasi bencana gempa bumi berbasis lokalitas dan keagamaan masyarakat Desa Bangunharjo Kecamatan Sewon Kabupaten Bantul. b) Penyusunan dan distribusi modul mitigasi bencana gempa bumi berbasis lokalitas dan keagamaan masyarakat Desa sebagai sumber referensi pengurus Masjid dalam menyebarluaskan tindakan pengurangan resiko bencana, c) Pendampingan pengurus masjid dalam penyuluhan kepada masyarakat desa tentang mitigasi bencana gempa bumi. 
Muthmainnah, Toto Hermawan, Suryanto, Indra Suharyanto,

Abdul Mughits, Akhmad Muhaini, Ali Imron

\section{Kondisi Kemasjidan Desa Bangunharjo}

Mayoritas penduduk Desa Bangunharjo adalah beragama Islam, di setiap pedukuhan terdapat masjid dan langgar sebagai sarana tempat ibadah warga muslim.Dari 17 dusun di Bangunharjo semuanya memiliki langgar sehingga dalam satu wilayah pedukuhan dapat dipastikan mempunyai beberapa tempat ibadah.Menurut data dari Kasie Kesra di desa Bangunharjo terdapat 31 buah masjid dan 1 gereja termasuk 1 kapel.

Tabel 1

Masjid di Desa Bangunharjo

\begin{tabular}{|c|c|c|}
\hline NO & NAMA MASJID & DUSUN \\
\hline 1 & Al Huda & Jotawang \\
\hline 2 & Ziadatu Huda & Jotawang \\
\hline 3 & Al Munir & Salakan \\
\hline 4 & Nurul Huda & Salakan \\
\hline 5 & Anni'mah & Randubelang \\
\hline 6 & Al Ikhsan & Randubelang \\
\hline 7 & Arrozaq & Randubelang \\
\hline 8 & Nurul Hujaj & Wojo \\
\hline 9 & Al Aqrob & Wojo \\
\hline 10 & Baiturrahman & Saman \\
\hline 11 & Baitunna'im & Saman \\
\hline 12 & Baitul Hadi & Druwo \\
\hline 13 & Al Hidayah & Druwo \\
\hline 14 & Al Falakh & Semail \\
\hline 15 & A1 Jamal & Semail \\
\hline 16 & Nurul Khasanah & Mredo \\
\hline 17 & Al Mujtaba & Mredo \\
\hline 18 & Nur Jannah & Mredo \\
\hline 19 & Al Ikhlas & Ngijo \\
\hline 20 & Al Huda & Sangkal \\
\hline 21 & Arrahman & Tarudan \\
\hline 22 & Nurul Huda & Ngoto \\
\hline 23 & Annur & Pandean \\
\hline 24 & Darussalam & Bakung \\
\hline 25 & Mujahadah & Mredo Kulon \\
\hline 26 & Baiturahman & Gatak \\
\hline 27 & Nur Iman & Widoro \\
\hline
\end{tabular}




\begin{tabular}{|l|l|l|}
\hline 28 & Al Ikhlas & Tanjung \\
\hline 29 & Nurul Huda & Jetak \\
\hline 30 & Al Jannah & Jurug \\
\hline 31 & Al Firdaus & Ngoto \\
\hline
\end{tabular}

Kondisi masjid desa pasca gempa bumi

Tahun 2006 merupakan merupakan tahun bencana bagi Dusun Bangunharjo Kecamatan Sewon kabupaten Bantul. Gempa bumi berskala richter tinggi telah merubah kondisi sarana dan prasarana desa termasuk masjid secara signifikan. Pergeseran arah kiblat masjid bisa disebabkan dari akibat bencana alam seperti gempa bumi (Muthmainnah et al. 2019) Sebagai gambaran ringkas, pada bagian ini digambarkan kondisi dua masjid desa ketika sejak pendidirian, saat gempa bumi dan kondisi sekarang.(Ali Imron, 2016)

Masjid Nurul khasanah

Masjid Nurjanah terletak di dusun Mredo Desa Bangunharjo Kecamatan Sewon Kabupaten Bantul . Didirikan oleh masyarakat dusun Mredo Wetan pada tahun 1977 dengan ukuran 7x7 m2. Lokasi Masjid Nurjanah merupakan tanah wakaf dari seorang sesepuh dusun yang bernama Bapak Darmo Sucipto. Ikrar wakaf dilakukan dengan ikrar bil lisan belum dicatatkan di KUA. Wakif Bapak Darmo Sucipto meninggal pada tahun 80 an.

Akibat gempa bumi tahun 2006 kerusakan tidak begitu besar dibanding yang lainnya. Namun karena ada permasalahan dalam status hokum tanah wakaf dan atas inisiatif salah satu keluarga wakif, wakaf masjid mengalami perubahan. Pengalihan dilakukan dengan membeli sebidang tanah dekat dengan masjid Nurjanah dan diwakafkan untuk dibangun Masjid baru dengan ukuran bangunan utama 7x7 m2 dan serambi samping kanan, kiri dan depan masing masing $3 \mathrm{~m}$, dengan nama Masjid Nurul Khasanah.yang berjarak 20 meter di sebelah timur laut Masjid Nurjanah.

Masjid Ar-Rahman

Masjid Ar-Rahman berada di dusun Tarudan Desa Bangunharjo Kecamatan Sewon.Menurut keterangan dari narasumber Masjid Ar-Rahman 
Muthmainnah, Toto Hermawan, Suryanto, Indra Suharyanto,

Abdul Mughits, Akhmad Muhaini, Ali Imron

berdiri pada tahun 1965 dengan status wakaf bi al-lisan karena belum ada Akta Ikrar Wakaf (AIW) oleh Pejabat yang berwenang pada saat itu. Masjid ArRahman berada di pinggir jalan raya tepatnya jalan penghubung dari Desa Bangunharjo ke Kecamatan Sewon.Ukuran luas pada saat itu adalah 7x7 m2 dengan wakif atas nama bapak Pringgo suwongso.Pada tahun 2006 saat terjadi gempa bumi Masjid Ar-Rahman lama roboh.

Pada tahun 2006 saat terjadi gempa bumi, Masjid Ar-Rahman roboh, Maka pada tahun 2006 Masjid Ar-Rahman direlokasi ke tempat yang lebih luas. Ukuran Masjid Ar-Rahman yang baru berukuran 13X13 m2. Peresmiannya dilakukan oleh Bupati Bantul Idham Samawi pada tahun 2007.(Sumardiyono, 2016)

\section{Pelaksanaan}

Focus Group Discussion (FGD)

Penyusunan modul mitigasi gempa bumi berbasis keagamaan diawali dengan pembentukan kelompok diskusi. Tujuannya semata untuk kemudahan kajian yang dilakukan, khususnya kelompok Al-Qur'an disertai kelompok pembahas kondisi nyata dalam geografis dan masyarakat akibat gempa bumi. Dari sumber tersebut ditelusuri penjabarannya juga dalam kitab tafsir dan fiqih yang berkaitan. Masing-masing kelompok mendiskusikan dan mencari khazanah yang dimiliki oleh Islam direlasikan dengan kondisi riil dalam masyarakat. Kelompok Al-Qur'an menelusuri ayat-ayat Al-Qur'an mengenai alam dan penciptaannya serta norma dasar yang dimiliki kitab suci itu. Kelompok lain mensurvei rujukan relevan tentang kondisi nyata dalam geografi dan masyarakat akibat gempa bumi. Penjelasannya pada kelompok pertama juga ditelusuri melalui kitab fiqh klasik (kitab kuning) maupun modern yang pernah ditulis oleh para fuqaha (ahli fikih) yang terkait dengan persoalan gempa bumi.

Dengan pengelompokan itu diharapkan hasil modul mitigasi gempa bumi memiliki akurasi dalam kesesuaian dengan situasi dan kondisi lingkungan social dan keagamaan di desa Bangun Harjo. Akurasi itu juga bisa dilihat dari rujukan yang bersumber dari Al-Qur'an yang merupakan sumber pokok ajaran Islam, dan kitab fiqh klasik maupun modern, yang merupakan 
hasil pemikiran para ulama berdasarkan pemahaman yang mendalam dari sumber asalnya, yaitu Al-Qur'an dan Hadits. Beberapa hasil pemikiran fiqh lingkungan hidup modern diutamakan memiliki relevansi yang kuat dengan persoalan gempa bumi Indonesia.

Hasil dari masing-masing kelompok diharapkan dapat dijadikan landasan bagi para pengurus takmir, khususnya dalam rangka mengembangkan pendidikan mitigasi gempa bumi, khususnya bidang keagamaan di kalangan warga muslim dan jama'ah takmir di lingkungan desa Bangun Harjo Kecamatan Sewon dan Kabupaten Bantul.

Sosialisasi

Dalam pengabdian ini, sosialisasi masih ditekankan pada tipe kedua. Selain untuk tujuan sesungguhnya, pilihan ini dimaksudkan untuk menarik respon dan kritik masyarakat desa Bangunharjo terhadap kesesuaian materi dengan kebutuhan mereka dalam meningkatkan kewaspadaan terhadap dampak bencana gempa bumi. Dlam pesoalan masjid, akurasi arah kiblat menjadi perhatian utama karena terkena damapak akibat pergeseran tanah lokasi akibat gempa bumi

Sosialisasi tentang tanggap bencana gempa terhadap masyarakat yang beraktifitas di daerah rawan gempa, yang dalam hal ini adalah masyarakat desa Bangunharjo masih tergolong minim. Oleh karena itu, dengan mengkaji keberadaan masjid dari sisi keagamaan, maka peran takmir masjid beserta sarana dan prasarananya merupakan salah satu aspek pendukung untuk mensosialisasikan pentingnya mitigasi bencana gempa bumi.

Pendampingan takmir masjid dan tokoh masyarakat Desa Bangunharjo dalam usaha mensosialisasikan mitigasi bencana gempa bumi kepada masyarakat setempat melalui modul yang telah dipersiapkan. Oleh karena itu, dengan keberadaan modul dan usaha sosialisasi tanggap bencana gempa bumi tersebut masyarakat diharapkan untuk dapat mengetahui bagaimana cara mengambil sikap dan pesan agar tidak panik saat terjadi gempa. Begitu juga saat sebelum dan setelah terjadinya gempa bumi. Lebih lanjut, dampak terjadinya gempa bumi yang dapat merusak bangunan masjid, dan mungkin mampu untuk menggeser sedikit struktur tanah perlu juga 
Muthmainnah, Toto Hermawan, Suryanto, Indra Suharyanto,

Abdul Mughits, Akhmad Muhaini, Ali Imron

dikorelasikan dengan keberadaan arah kiblat bagi tiap-tiap masjid ataupun mushalla di Desa Bangunharjo.

Optimalisasi peran takmir masjid dan kepengurusannya, dari sisi keagamaan bertujuan untuk menciptakan kualitas masyarakat yang tanggap terhadap gempa bumi. Sosialisasi ini dilakukan dengan cara memberikan informasi yang lengkap tentang gempa dan bagaimana cara-cara yang harus diambil ketika gempa terjadi ataupun sebelum terjadi kepada masyarakat supaya lebih waspada dan tanggap pada gempa dan lingkungan disekitarnya, termasuk dalam bidang keagamaan, khususnya tata letak arah kiblat.

\section{Penutup}

Masjid di Desa Bangun Harjo Kecamatan Sewon Kabupaten Bantul sudah layak untuk terlibat dalam kegiatan mitigasi gempa bumi di desanya. Mereka bahkan harus diajak bicara tentang bagaimana mengantisipasi bencana gempa bumi secara dini melalui meitigasi. Mereka dapat menjadi Pembina lingkungan gerakan mitigasi terutama dalam bencana gempa bumi di desa Bangun Harjo. takmir dapat menjadi salah satu ujung tombak dalam sosialisasi mitigasi gempa bumi bidang keagamaan di desanya. takmir bisa menjadikan persoalan pasca gempa bumi merupakan salah satu permasalahan bersifat publik yang mudah dipecahkan dengan memotivasi partisipasi masyarakat dan rumah tangga serta serta jama'ah melalui kekuatan fungsinya dalam menyebarkan figh Islam. Meski demikian, Selama perjalanan pelatihan, mereka juga mendapati beberapa hal yang harus dibenahi agar mitigasi gempa bumi bisa mendorong penciptaan kesadaran masayrakat di desanya termasuk dalam pelaksanaan FGD dan sosialisasi. Pertama, Kesadaran takmir masjid potensi lembaganya dalam peran persuasive di masyarakat sanga besar sehingga perlu diarahakan guna memperkuat perwujudan masjid tangguh. Kedua, kekuatan partisipasi masyarakat masih bisa digali lebih jauh dalam sosialisasi sehingga penyusunan modul yang lebih baik dengan pembagian usia belajar yang disesuaikan, yaitu untuk sosialisasi siswa sekolah atau peserta dewasa harus dipertimbangkan. Hal itu mengarahkan kepada kebutuhan tindak lanjut pada penyusunan kurikulum mitigasi bencana yang lebih baik sebagai pelengkap modul sosialisasi. Ketiga, 
Produk peraturan daerah belum mendukung sepenuhnya budaya mitigasi gempa bumi.

Konsep Integrasi dalam pembangunan budaya waspada gempa melalui kegiatan mitigasi bencana berbasis masjid juga harus tercermin dalam implementasinya dalam masyarakat. Pemerintah, masyarakat dan individu warga harus bersama-sama menyatukan visi, misi, tekad dan langkah dalam penciptaan budaya waspada gempa. Begitu pula kesatuan langkah antara pengurus dan Jama'ah takmir. Pengurus takmir dapat dilibatkan sejak perencanaan sampai taraf monitoring dan evaluasi program ini. Inilah konsep pemberdayaan takmir dengan pendekatan partisipatoris.

\section{Daftar Pustaka}

Aditya, Trias. 2010. Visualisasi Risiko Bencana Dalam Peta. Yogyakarta: Badan Kesbanglinmas Provinsi DIY, PPMU DIY, SCDRR.

Arifin, Zainul. 2017. "Akurasi Google Earth Dalam Pengukuran Arah Kiblat." Ulumuddin: Jurnal Ilmu-ilmu Keislaman 7(2):137-46.

Arifin, Zainul. 2018. "Toleransi Penyimpangan Pengukuran Arah Kiblat." ELFALAKY: Jurnal Ilmu Falak 2(1):62-75.

Dahalan, Abdul Rahman bin Ahmad, Intan Munirah Binti Zakaria, Nour Tiara Natasha Binti Mohamed Azizan, dan Nur Isharra Binti Abdullah. 2015. "Transformation of Masjid: Empowerment of Muslims Economy through E-Halal One Stop Centre (E-HOSC)." International Journal of Management and Commerce Innovations 3(1):113-21.

Dwisiwi R.S., Surachman, J. Sudomo, dan Y. Wiyatmo. 2012. "Pengembangan Teknik Mitigasi Dan Managemen Bencana Alam Gempa Bumi Bagi Komunitas SMP DI Kabupaten Bantul Yogyakarta." Prosiding Seminar Nasional Penelitian.

Fauroni, Lukman, Munawar Ahmad, dan Awan Kostradiharto. 2016. PTKI Entrepreneur Gagasan dan Praktik. diedit oleh E. B. Wiranto. Yogyakarta: Kurnia Kalam Semesta.

Imroatun, Imroatun. 2015. "Masjid dan Pengembangan Wawasan Anak Usia Dini dalam Pelestarian Lingkungan Hidup Nasional." Ulumuddin: Jurnal Ilmu-ilmu Keislaman 5(1):21-28.

Maarif, Syamsul. 2012. Pikiran dan Gagasan Penanggulangan Bencana di Indonesia. Jakarta: BNPB.

Mohit, Mohammad Abdul, Rustam Khairi Zahari, Muhamad Abu Eusuf, dan Md Yusouf Ali. 2014. "Role Of The Masjid In Disaster Management: Preliminary Investigation Of Evidences From Asia." JOURNAL OF ARCHITCTURE, PLANNING \& CONSTRUCTION MANAGEMENT 4(1):1-16.

Mughits, Abdul. 2016. "Kajian Ilmu Falak di Pesantren Salaf di Jawa Tengah dan Jawa Timur." Asy-Syir'ah: Jurnal Ilmu Syari'ah dan Hukum 50(2):379_ 
Muthmainnah, Toto Hermawan, Suryanto, Indra Suharyanto,

Abdul Mughits, Akhmad Muhaini, Ali Imron

98. doi: 10.14421/ASY-SYIR'AH.2016.502-04.

Musaropah, Umi, Suharto Suharto, Daluti Delimanugari, Agus Suprianto, Rubini Rubini, Retno Kurnianingsih, dan Citra Ayudiati. 2019. "Pengembangan Kewirausahaan Berbasis Industri Kreatif Bagi Jamaah Wanita Majelis Taklim Di Desa Kepek." Nuansa Akademik: Jurnal Pembangunan Masyarakat 4(2):79-90.

Muthmainnah. 2016. "Falak Dan Ilmu Yang Berkaitan Dengannya." Ulumuddin: Jurnal Ilmu-ilmu Keislaman 6(1):49-59.

Muthmainnah, Muthmainnah, Zainul Arifin, Toto Hermawan, Barid Barid, dan Akhmad Muhaini. 2019. "Analisis Implementasi Program Gerakan Arah Kiblat 1000 Masjid/ Mushola di Kabupaten Sleman." Nuansa Akademik: Jurnal Pembangunan Masyarakat 4(2):91-104.

Mutmainnah, Mutmainnah. 2017. "Kiblat Dan Kakbah Dalam Sejarah Perkembangan Fikih." Ulumuddin: Jurnal Ilmu-ilmu Keislaman 7(1):1-16.

Nadjih, Difla, dan F. Setiawan Santoso. 2015. "Sosialisasi Fikih Lingkungan Usulan Pemberdayaan Majelis Taklim Di Desa Nelayan." Ulumuddin: Jurnal Ilmu-ilmu Keislaman 5(2):65-73.

Nuroini, Evi Dahliyatin. 2010. "Pengaruh Pergeseran Lempeng Bumi Terhadap Penentuan Arah Kiblat Masjid-Masjid Di Kota Yogyakarta." Universitas Islam Negeri Maulana Malik Ibrahim Malang.

Prihantoro, Agung, dan Fattah Hidayat. 2019. "Melakukan Penelitian Tindakan Kelas." Ulumuddin: Jurnal Ilmu-ilmu Keislaman 9(1):49-60.

Rakhman, Arie Noor, dan Istiana Kuswardani. 2012. "Studi Kasus Gempa Bumi Yogyakarta 2006: Pemberdayaan Kearifan Lokal Sebagai Modal Masyarakat Tangguh Menghadapi Bencana." Hal. 185-93 in Prosiding Seminar Nasional Aplikasi Sains \& Teknologi (SNAST) Periode III. Yogyarta.

RI. 2008. Peraturan Pemerintah RI Nomor 21 Tahun 2008 Tentang Penyelenggaraan Penanggulangan Bencana.

Santoso, Fattah Setiawan, Diflah Nadjih, dan Imam Samroni. 2015. Penguatan Budaya Ramah Lingkungan Berbasis Fikih Di Kampung Nelayan Wilayah Poncosari Srandakan Bantul-DIY, Laporan Akademik Program Bantuan Peningkatan Mutu Pengabdian Kepada Masyarakat. Jakarta.

Saputra, Darma Eka, Raizal Fahmi, Rifa Khaerunnisa, Satria Bijaksana, dan Septian Firmansyah. 2010. Masjid Tangguh, Handling Disasters and People Development in One Harmony. Bandung: YPM Salman ITB.

Setyawan, Nicky, dan Nurul Khakim. 2012. "Penyusunan Peta Risiko Bencana Gempa Bumi Skala Mikro Berdasarkan Kerusakan Bangunan." Jurnal Bumi Indonesia 1(2).

Zaeniah, Siti Adibatul. 2013. "Evaluasi RTRW Kabupaten Bantul, Daerah Istimewa Yogyakarta Berdasarkan Zona Kerawanan Bencana Gempa Bumi." Program Pascasarjana Universitas Hasanuddin Makassar. 